\title{
Tinospora cordifolia consumption ameliorates changes in kidney chondroitin sulphate/dermatan sulphate in diabetic rats
}

\author{
Darukeshwara Joladarashi, Nandini D. Chilkunda and Paramahans V. Salimath* \\ Department of Biochemistry and Nutrition, Central Food Technological Research Institute, Mysore 570 020, Karnataka, India
}

(Received 17 November 2011 - Final revision received 25 April 2012 - Accepted 28 May 2012)

Journal of Nutritional Science (2012), vol. 1, e7, page 1 of 12

doi:10.1017/jns.2012.6

Abstract

Diabetes is known to alter kidney extracellular matrix (ECM) components. Chondroitin sulphate (CS)/dermatan sulphate (DS), an ECM component, which plays an essential role in kidney is altered during diabetes. The focus of this study has been to examine the effect of Tinospora cordifolia (TC) consumption, a potent plant widely used to treat diabetes, on kidney CS/DS. Experimentally induced diabetic rats were fed with diet containing TC at 2.5 and $5 \%$ levels and the effect of it on kidney CS/DS was examined. The CS/DS content and CS:heparan sulphate ratio which was decreased during diabetic condition were ameliorated in TC-fed groups. Disaccharide composition analysis of CS/DS by HPLC showed that decreases in 'E' units and degree of sulphation were modulated in $5 \%$ TC-fed groups. Apparent molecular weight of purified CS/DS from the control rat kidney was found to be $38 \mathrm{kDa}$ which was decreased to $29 \mathrm{kDa}$ in diabetic rat kidney. Rats in $5 \% \mathrm{TC}$-fed groups showed chain length of $38 \mathrm{kDa}$ akin to control rats. Expression of chondroitin 4-Osulfotransferase-1, dermatan 4-O-sulfotransferase-1 and $N$-acetylgalactosamine 4 sulphate 6-O-sulfotransferase, enzymes involved in the synthesis of ' $\mathrm{E}$ ' units which was reduced during diabetic condition, was significantly contained in the $5 \%$ TC-fed group. Purified CS/DS from $5 \%$ TC-fed group was able to bind higher amounts of ECM components, namely type IV collagen and laminin, when compared with untreated diabetic rats. The present results demonstrate that consumption of a diet containing TC at the $5 \%$ level modulates changes in kidney CS/DS which were due to diabetes.

Key words: Tinospora cordifolia: Glycosaminoglycans: Diabetes: Chondroitin sulphate/dermatan sulphate: Kidneys

Diabetes mellitus, a chronic metabolic disorder, is associated with an increased risk of micro-vascular and macro-vascular complications that include nephropathy, retinopathy, neuropathy, coronary artery disease, peripheral arterial disease and stroke $^{(1)}$. Diabetes, if left uncontrolled, causes progressive alterations in kidney structure and function ${ }^{(2)}$. This is basically due to changes in extracellular matrix (ECM) components, namely heparan sulphate (HS), laminin, fibronectin, type IV collagen, etc. ${ }^{(3)}$. Although HS is decreased in diabetic rat kidney, it has been observed that it increases in other ECM components ${ }^{(4,5)}$. Chondroitin sulphate (CS)/dermatan sulphate (DS) are sulphated glycosaminoglycans (GAG) characterised by the disaccharide glucuronic acid/iduronic acid 1-3 linked to $N$-acetyl-D-galactosamine (GalNAc). They can be differentially sulphated resulting in microheterogeneity and fine structural variations bringing about differences in their nature and functional properties ${ }^{(6)}$. Recently, for the first time our studies showed that CS/DS, one of the ECM components in kidney which is present in small but significant amounts, undergoes structural changes resulting in changes in functional properties ${ }^{(7)}$. A significant decrease in its amount was observed as a result of diabetes. Furthermore, there was a significant reduction in one of the disaccharides - the ' $\mathrm{E}$ ' unit which is characterised by sulphation at 4-O and 6-O positions of GalNAc residues followed by a

\footnotetext{
Abbreviations: AIN, American Institute of Nutrition; 2AB 2-aminobenzamide; CS, chondroitin sulphate; DS, dermatan sulphate; DMMB, 1,9-dimethylmethylene blue; ECM, extracellular matrix; GAG, glycosaminoglycan; GalNAc, N-acetyl-D-galactosamine; GFR, glomerular filtration rate; HS, heparan sulphate; HexUA, hexuronic acid; IdoA-Liduronic acid; SFC, starch-fed control; SFD, starch-fed diabetic; STZ, streptozotocin; TC, Tinospora cordifolia; TFD, TC-fed diabetic.
}

* Corresponding author: Dr P. V. Salimath, fax +91821 2517233, email salimath1954@gmail.com

(C) Central Food Technological Research Institute 2012. The online version of this article is published within an Open Access environment subject to the conditions of the Creative Commons Attribution-NonCommercial-ShareAlike licence <http://creativecommons.org/licenses/by-nc-sa/2.5/>. The written permission of Cambridge University Press must be obtained for commercial re-use. 
decrease in the degree of sulphation ${ }^{(7)}$. CS/DS plays an important role in a wide array of biological activities and has been implicated in fetal kidney morphogenesis ${ }^{(8)}$ and recently in permselective properties of glomerular basement membrane ${ }^{(9)}$. These molecules show heterogeneity in terms of chain length, degree of sulphation and domain structures.

Cells in a high-glucose milieu, as in diabetes, show alterations in the normal metabolic processes ${ }^{(10)}$. Hence, it is imperative to control glucose levels. Apart from insulin and drugs, diet and exercise are known to play an important role in the management of diabetes. Drugs currently available have limitations in terms of adverse effects and high rates of secondary failure ${ }^{(11)}$. Plants rich in nutraceuticals have garnered increased attention in recent years in the management of diabetes ${ }^{(12)}$. Plants such as Momordica, Neem seed kernel powder and Averrboa bilimbi ${ }^{(13,14)}$ have been shown to have hypoglycaemic properties with the ability to correct the metabolic derangements caused by experimental diabetes. Furthermore, nutraceuticals can act through various mechanisms to bring about beneficial effect ${ }^{(15)}$. Our earlier studies have shown that a diet rich in fibres and butyric acid has a beneficial effect on some of the components of kidney ECM in diabetic rats ${ }^{(16,17)}$.

Tinospora cordifolia (TC) is a potent plant material that is widely used in Indian Ayurvedic medicine as a tonic, vitaliser, immunomodulator and as a remedy for metabolic disorders ${ }^{(18)}$. It is a large, glabrous, deciduous climbing succulent shrub, belonging to the Menispermaceae family which is commonly found in hedges. The plant stem has been considered as an indigenous source of medicine with anti-diabetic ${ }^{(19)}$, immunomodulatory ${ }^{(20)}$, hepatoprotective ${ }^{(21)}$ and anti-pyretic ${ }^{(22)}$ actions. Although TC consumption shows beneficial effects on a wide range of biological activities, no study has been done so far with respect to ECM components of kidney as a result of diabetes. This study was therefore undertaken to determine whether consumption of a diet supplemented with TC will have a positive effect on CS/ DS, an ECM component of the kidney which was earlier seen to undergo diabetes-induced changes ${ }^{(7)}$.

\section{Experimental methods}

\section{Chemicals}

Chondroitinase AC (EC 4.2.2.5) and chondroitinase B (EC 4.2.2) from Flavobacterium heparinum, hyaluronidase (EC 4.2.2.1) from Streptomyces byalurolyticus, CS-56 (anti-CS) antibody, type IV collagen from Engelbreth-Holm-Swarm murine sarcoma basement membrane, laminin from Engelbreth-Holm-Swarm murine sarcoma basement membrane, streptozotocin (STZ), 2-aminobenzamide (2AB), sodium cyanoborohydride $\left(\mathrm{NaBH}_{3} \mathrm{CN}\right)$, 1,9-dimethylmethylene blue (DMMB) and primers for semi-quantitative RT-PCR were from Sigma-Aldrich Chemical Co. Chondroitinase ABC from Proteus vulgaris, CS B from porcine kidney and standard CS unsaturated disaccharides were obtained from Associates of Cape Cod. An anti-type IV collagen was from AbCam. An RT-PCR kit was procured from Genei Pvt Ltd. A glucose oxidase/peroxidase kit was purchased from Span Diagnostic Limited. All other chemicals and reagents used were of analytical grade.

\section{Plant material}

Tinospora cordifolia (willd.) Miers ex. Hook.f. \& Thoms stems were collected from Central Food Technological Research Institute campus, Mysore, Karnataka, India. The plant was authenticated by depositing herbarium sheets at the Herbarium Collection Centre (SKU accession no. 11199), Sri Krishnadevaraya University, Anantapur, India. The leaves were separated from stems manually and the stems were cut into small pieces and dried at $37^{\circ} \mathrm{C}$ for $12 \mathrm{~h}$. It was then finely powdered and was kept in an air-tight container in a refrigerator until the time of use.

\section{Animals, diet and time of experiment}

Male Wistar rats (OUTB-Wistar IND cftri) weighing about $120-140 \mathrm{~g}$ were taken for the study from the Institute Animal House Facility. The study had the clearance of the Institutional Animal Ethical Committee. The rats were fed with an American Institute of Nutrition (AIN)-76 diet ${ }^{(23)}$ and had free access to food and water.

\section{Experimental induction of diabetes}

To induce diabetes, the rats were fasted for $8 \mathrm{~h}$ and injected with STZ at a dose of $55 \mathrm{mg} / \mathrm{kg}$ body weight ${ }^{(24)}$ in freshly prepared $0.1 \mathrm{M}$-citrate buffer, $\mathrm{pH}$ 4.5. The control animals received citrate buffer alone. Diabetic status was confirmed by estimating fasting blood glucose level and urine sugar after $72 \mathrm{~h}$ of STZ injection. Animals with fasting blood glucose levels $>2400 \mathrm{mg} / 1$ were selected for the study.

\section{Experimental protocol}

After confirming hyperglycaemia, animals were grouped into four groups which were named tentatively as follows: starch-fed control (SFC), starch-fed diabetic (SFD) and 2.5 and $5 \%$ TC-fed diabetic (TFD) (2.5\% TFD and $5 \%$ TFD, respectively). SFC and SFD groups received the AIN-76 basal diet, whereas TFD groups received the AIN-76 diet supplemented with TC, wherein starch was replaced with 2.5 and $5 \%$ stem powder. At the end of the experimental period $(60 \mathrm{~d})$, the groups had the following number of animals: SFC, $n 6$, SFD, $2.5 \%$ TFD and $5 \%$ TFD, $n$ 11 each. Animals were killed under anaesthesia and blood was collected by cardiac puncture. Kidneys were removed, washed in cold saline, blotted with filter paper and weighed. A portion of kidney was used to isolate mRNA, while another portion was fixed in $10 \%$ buffered formalin for histological studies. The remaining tissue was used to isolate CS/DS.

\section{Determination of kidney function}

Kidney functions were assessed by measuring kidney index, glomerular filtration rate (GFR), microalbuminuria and glomerular area. Kidney index (KI) was measured by using the formula:

$$
\mathrm{KI}=\frac{\text { kidney weight }(\mathrm{g})}{\text { body weight }(\mathrm{g})} \times 1000 .
$$


Creatinine clearance was used to measure the GFR levels in control, diabetic and TC-fed rats. Creatinine levels in urine and serum were estimated by using commercially available kit from Span Diagnostics $^{(25)}$. GFR was calculated using the formula ${ }^{(26)}$ :

$$
\begin{aligned}
& \text { GFR }(\mathrm{ml} / \mathrm{min}) \\
& =\frac{\text { urinary creatinine }(\mathrm{mg} / \mathrm{l}) \times \text { urine volume }(\mathrm{ml}) \times 1000(\mathrm{~g})}{\text { plasma creatinine }(\mathrm{mg} / \mathrm{l}) \times \text { body weight }(\mathrm{g}) \times 1440(\mathrm{~min})}
\end{aligned}
$$

Albumin in urine was estimated by fluorimetry using Albumin Blue $580^{(27)}$. To measure glomerular areas, kidneys were paraffin blocked and $5 \mu \mathrm{m}$ sections were made. These paraffin sections were incubated twice with xylene at room temperature for $5 \mathrm{~min}$ each and hydrated with $100 \%$ ethanol, followed by 95,85 , and $80 \%$ ethanol for $5 \mathrm{~min}$ each. These sections were stained with haematoxylin and eosin and the area of glomerulus was calculated using the Image J software analysis tool for at least twenty glomeruli per rat.

\section{Isolation and purification of chondroitin sulphate/dermatan} sulphate from control, diabetic and TC-fed rat kidney

The defatted and dried kidney was powdered thoroughly and suspended in $20 \mathrm{ml}$ of phosphate buffer $(0 \cdot 1 \mathrm{M}$, $\mathrm{pH} 6 \cdot 5)$. Papain solution (10 $\mathrm{mg}$ papain in $1 \mathrm{ml}$ of phosphate buffer containing EDTA $(0 \cdot 005 \mathrm{M}))$ was first activated by keeping at $65^{\circ} \mathrm{C}$ for $30 \mathrm{~min}$ in a water bath and an aliquot of $1 \mathrm{ml}$ was added to the tissue suspension and digested for $2 \mathrm{~d}$ at $65^{\circ} \mathrm{C}$ in an oven. Periodically, at the end of $24 \mathrm{~h}$ an aliquot of fresh enzyme solution was added. After digestion, the reaction mixture was centrifuged and a one-third volume of $40 \%$ TCA was added to the supernatant to precipitate the proteins. The precipitate was discarded after centrifugation ( $3000 \mathrm{~g}$ for $15 \mathrm{~min}$ ) and four volumes of ethanol containing $1.2 \%$ potassium acetate were added and left at $4^{\circ} \mathrm{C}$ to precipitate the GAG. The precipitate was collected by centrifugation ( $3000 \mathrm{~g}$ for $15 \mathrm{~min}$ ) and reconstituted with water ${ }^{(28)}$. To remove HS, the total GAG obtained after alcohol precipitation was treated with freshly prepared nitrous acid, which was generated by mixing equal volumes of $0.5 \mathrm{~mm}$ of $\mathrm{H}_{2} \mathrm{SO}_{4}$ and $0.5 \mathrm{~mm}$ of barium nitrite and left at room temperature for $40 \mathrm{~min}^{(29)}$. An aliquot of freshly prepared nitrous acid was added again and the incubation continued for a further $40 \mathrm{~min}$. The treated sample was neutralised with 0.5 $\mathrm{M}-\mathrm{Na}_{2} \mathrm{CO}_{3}$ and desalted on a column of Sephadex G-50 $(1 \times$ $56 \mathrm{~cm}$ ) using $0.2 \mathrm{M}$-ammonium bicarbonate as the eluent at a flow rate of $0.6 \mathrm{ml} / \mathrm{min}$. In all fractions, sulphated $\mathrm{GAG}$ were estimated by the DMMB method ${ }^{(30)}$. The putative CS/ DS-rich fractions were pooled and freeze-dried repeatedly by reconstituting in water. To remove hyaluronic acid, reconstituted CS/DS was digested with hyaluronidase from S. byalurolyticus.

\section{Chondroitin sulphate/dermatan sulphate disaccharide composition analysis}

The disaccharide composition of purified CS/DS from all four groups was analysed by digesting with $10 \mathrm{mIU}$ of chondroitinase $\mathrm{ABC}$ for $1 \mathrm{~h}$ at $37^{\circ} \mathrm{C}^{(31)}$. Briefly, $4 \mu \mathrm{g}$ (as sulphated GAG) purified CS/DS was digested with chondroitinase ABC and the enzyme heat killed after the incubation period and was labelled with $2 \mathrm{AB}^{(32)}$. Excess $2 \mathrm{AB}$ was removed by paper chromatography using a solvent system consisting of butanol-ethanolwater $(4: 1: 1)^{(33)}$. The 2AB-labelled disaccharides were diluted to $200 \mu \mathrm{l}$ with $16 \mathrm{~mm}-\mathrm{NaH}_{2} \mathrm{PO}_{4}$ and an aliquot analysed by SAX-HPLC on a PA-03 silica column (YMC-Pack PA) by gradient elution using a solvent system of 16 and $530 \mathrm{~mm}-\mathrm{NaH}_{2} \mathrm{PO}_{4}$ run over a period of $1 \mathrm{~h}$ by fluorescence detection with excitation and emission wavelengths set at 330 and $420 \mathrm{~nm}$, respectively ${ }^{(32)}$.

\section{Determination of hybrid structure of purified chondroitin sulphate/dermatan sulphate}

The hybrid structure of purified CS/DS from SFC, SFD and TFD groups was determined by digesting with $10 \mathrm{mIU}$ of chondroitinase $\mathrm{ABC}$ or $2 \mathrm{mIU}$ of chondroitinase $\mathrm{AC}$ at $37^{\circ}$ $\mathrm{C}$ or $2 \mathrm{mIU}$ of chondroitinase $\mathrm{B}$ at $30^{\circ} \mathrm{C}$ for $1 \mathrm{~h}$ in a total volume of $20 \mu \mathrm{l}^{(34)}$. After each enzymatic treatment, an aliquot was taken to estimate the resistant structure of CS/DS by complexation with the metachromatic dye DMMB, which complexes with sulphated GAG and long oligosaccharides, but not with short oligosaccharides. Briefly, $30 \mu \mathrm{l}$ of 0.05 M-acetate buffer ( $\mathrm{pH}$ 6.8) and $400 \mu$ l of DMMB solution were added to a $10 \mu \mathrm{l}$ aliquot of the aforementioned digest, and the absorbance was measured at $525 \mathrm{~nm}$. The loss of reactivity towards the dye was checked after each digestion, and the amount remaining was calculated based on the absorbance value using the calibration curve obtained with varying amounts of standard commercial CS/DS (0.4-4.0 $\mu \mathrm{g})$. The amount of GAG before digestion was taken as $100 \%$.

\section{Molecular weight determination of purified chondroitin sulphate/dermatan sulphate}

Molecular weight was determined using a Superdex 200 column $(10 \times 330 \mathrm{~mm})$ calibrated with known molecular weight markers, including dextran preparations (average molecular weights of 10, 40 and $200 \mathrm{kDa}$ ), HS from bovine intestinal mucosa (average molecular weight of $7.5 \mathrm{kDa}$ ), and heparin from porcine intestinal mucosa (average molecular weight of $6 \mathrm{kDa}$ ). Elutions of dextrans were monitored by the phenol sulphuric acid method for total sugar ${ }^{(35)}$. The purified CS/DS (10 $\mu$ g as sulphated GAG) from control, diabetic and TC-fed groups was loaded separately onto the column and eluted with $0.2 \mathrm{M}$-ammonium acetate buffer at a flow rate of $0.3 \mathrm{ml} / \mathrm{min}$. The fractions were collected at 3-min intervals and evaporated to dryness. Sulphated GAG were estimated by the DMMB assay. Apparent molecular weight was determined by extrapolating the peak elution volume obtained with that of known molecular weight masses.

mRNA expression studies of chondroitin sulphate/dermatan sulphate sulphotransferases involved in synthesis of the ' $E$ ' disaccharide unit

Total RNA was isolated from $100 \mathrm{mg}$ of freshly harvested rat kidney by the Trizol method. The concentration of RNA was determined by absorption ratio at 260 and $280 \mathrm{~nm}$ and quality 
was checked by using formaldehyde gel electrophoresis for $28 \mathrm{~S}$ and $18 \mathrm{~S}$ RNA. The isolated RNA was converted into cDNA by using a GeNei ${ }^{\text {TM }}$ M-MuLV RT-PCR kit. cDNA obtained by reverse transcription was subjected to amplifications using primers corresponding to chondroitin 4-Osulfotransferase-1-forward primer 5'-GAAGCACCTGGTGGT GGATG-3', reverse primer 5'-GTAGTTCGGGTGGACT'T'T GCATAG-3', dermatan 4-O-sulphotransferase-1-forward primer 5'-TAGGGCCCT'TACCTCACAGC-3', reverse primer 5'-AAT GACATGGGCCACACACC-3', N-acetylgalactosamine 4 sulphate 6-O-sulfotransferase-forward primer 5'-ATCACAGT CATCAGGCGTGC-3', reverse primer 5'-CCCAGT'T'T CGT'TGCCCTCA-3', and actin forward primer 5'-TCATG AAGTGTGACGTTGACATCCGT-3', reverse primer 5'-CCT AGAAGCAT'T'TGCGGTGCACGATG-3'.

The reaction mixture included $2 \mu \mathrm{l}$ of $\mathrm{cDNA}, 2 \cdot 5 \mu \mathrm{l}$ of $10 \times$ PCR buffer, $0.5 \mu \mathrm{l}$ of dNTP (10 mM), $1 \mu \mathrm{l}$ (1.5 units) Taq polymerase, $18 \mu \mathrm{l}$ of diethylpyrocarbonate water and $1 \mu \mathrm{l}$ each of forward and reverse primers $(10 \mathrm{pmol})$. The thermal cycling programme consisted of $3 \mathrm{~min}$ at $94^{\circ} \mathrm{C}$, followed by thirty-five cycles of $30 \mathrm{~s}$ at $94^{\circ} \mathrm{C}$ and $1 \mathrm{~min}$ at $72^{\circ} \mathrm{C}$. The amplicons thus obtained were checked by running $1.5 \%$ agarose gel electrophoresis. To account for the variability in total RNA input, the expressions of the enzyme were normalised to actin levels in the samples. Densitometry of the amplicons was recorded and calculated using EASY WIN-32 Image software. Reverse transcription and amplification were performed independently for at least five rats per group in duplicates and relative fold expressions compared with actin levels are expressed as mean values and standard deviations.

\section{Solid state binding immunoassay of chondroitin sulphate/ dermatan sulphate preparations to type IV collagen and laminin}

Binding of CS/DS to varying amounts of ECM components such as type IV collagen and laminin was carried out by immobilising the CS/DS preparation individually from all four groups (100 ng) on poly-L-lysine-coated wells (400 ng/well) overnight. The wells were blocked with $1 \%$ bovine serum albumin in PBS at $37^{\circ} \mathrm{C}$ for $1 \mathrm{~h}$. The components to be tested for binding were added individually in varying amounts for overnight binding. Excess components were washed off and the amount bound was determined by adding specific primary antibody (for type IV collagen and laminin) followed by alkaline phosphatase tagged secondary antibody. Colour was developed by adding a chromogenic substrate $p$-nitrophenyl phosphatase and absorbance noted at $405 \mathrm{~nm}$. Specificity of binding was ascertained by digesting CS/DS with the enzyme chondroitinase $\mathrm{ABC}$ after immobilising them.

\section{Analytical methods}

Fasting blood glucose was estimated by the enzymatic glucose oxidase-peroxidase kit method ${ }^{(36)}$ and urine sugar was estimated by the dinitrosalicylic acid method.

\section{Statistical analysis}

Data, expressed as mean values and standard deviations, were analysed by one-way ANOVA followed by Duncan's multiple range test to compare between control and treated groups. $P$ values less than 0.05 were considered to be statistically significant. All statistical analyses were performed using SPSS statistical software package version 13.0 (SPSS, Inc.).

\section{Results}

\section{Effect of Tinospora cordifolia on body weight, fasting} blood glucose, urine output and urine sugar

Male Wistar rats experimentally induced with diabetes using STZ were used for the study. Age-matched rats that were injected with buffer served as controls. Animals were fed with the experimental diets for $60 \mathrm{~d}$. No difference was observed in the pattern of diet intake among diabetic animals albeit it was marginally higher when compared with control animals in the initial 3 weeks (data not shown). This indicates that there were no issues with palatability. Diabetic rats lost body weight compared with non-diabetic control rats. On the other hand, diabetic animals supplemented with TC marginally gained weight when compared with non-supplemented diabetic rats. Diabetic rats also exhibited increased fasting blood sugar, urine output and urine sugar consistent with diabetic condition which was significantly ameliorated in TC-fed rats (Table 1$)$.

Table 1. Effect of Tinospora cordifolia (TC) on body weight, fasting blood sugar, urine output and urine sugar in control and diabetic rats (Mean values and standard deviations)

\begin{tabular}{|c|c|c|c|c|c|c|c|c|}
\hline \multirow[b]{2}{*}{ Parameters } & \multicolumn{2}{|c|}{$\operatorname{SFC}(n 6)$} & \multicolumn{2}{|c|}{ SFD $(n 11)$} & \multicolumn{2}{|c|}{$2.5 \%$ TFD $(n 11)$} & \multicolumn{2}{|c|}{$5 \%$ TFD $(n 11)$} \\
\hline & Mean & $\mathrm{SD}$ & Mean & SD & Mean & SD & Mean & SD \\
\hline \multicolumn{9}{|l|}{ Body weight (g) } \\
\hline Initial & $152 \cdot 42$ & 1.70 & 160.59 & 1.71 & 168.85 & $2 \cdot 13$ & $167 \cdot 85$ & 1.12 \\
\hline Final & $313 \cdot 68$ & 17.99 & $148 \cdot 80^{*}$ & $2 \cdot 16$ & $179.63+$ & 13.47 & $200.09+$ & 5.97 \\
\hline Gain & $161 \cdot 26$ & $11 \cdot 27$ & $-11 \cdot 79^{*}$ & 2.98 & $10.94 \dagger$ & 1.31 & $37.42 \dagger$ & 2.67 \\
\hline \multicolumn{9}{|c|}{ Fasting blood sugar (mg/l) } \\
\hline Initial & 980 & 51.5 & $2580^{*}$ & 89.0 & 2610 & $77 \cdot 1$ & 2530 & 99.0 \\
\hline Final & $1061 \cdot 2$ & 74.7 & $3499 \cdot 0^{*}$ & 73.9 & $2016 \cdot 6+$ & 121.3 & $1726 \cdot 3+$ & 94.1 \\
\hline Urine output (ml/d) & 14.90 & $2 \cdot 24$ & $80.40^{*}$ & 3.70 & $59.65 t$ & $4 \cdot 10$ & $47.30+$ & 3.90 \\
\hline Urine sugar $(g / d)$ & 0.19 & 0.04 & $7.99^{\star}$ & 0.59 & $5.44 \dagger$ & 0.62 & $4.22 \dagger$ & 0.64 \\
\hline
\end{tabular}

SFC, starch-fed control; SFD, starch-fed diabetic; TFD, TC-fed diabetic (2.5 and $5 \%$ ).

${ }^{*}$ Mean value was significantly different from that of the SFC rats $(P<0.05)$.

† Mean value was significantly different from that of the SFD rats $(P<0.05)$ 
Effect of Tinospora cordifolia on kidney index, glomerular filtration rate, microalbuminuria and glomerular area

There was a 3-fold increase in kidney index in diabetic rats when compared with non-diabetic control rats, which was significantly decreased at $5 \%$ TC supplementation (Fig. 1(A)). GFR, measured in terms of creatinine clearance, was significantly increased in diabetic rats by 8 -fold and was ameliorated to various extents in TC-fed groups (Fig. 1(B)). Diabetic rats also showed high amounts of microalbumin in urine. Feeding diabetic rats with TC significantly ameliorated microalbuminuria (Fig. 1(C)). An increase in glomerular area, which is one of the hallmarks of diabetes in diabetic rats, was significantly ameliorated in rats supplemented with $5 \%$ TC (Fig. 2).

(A)

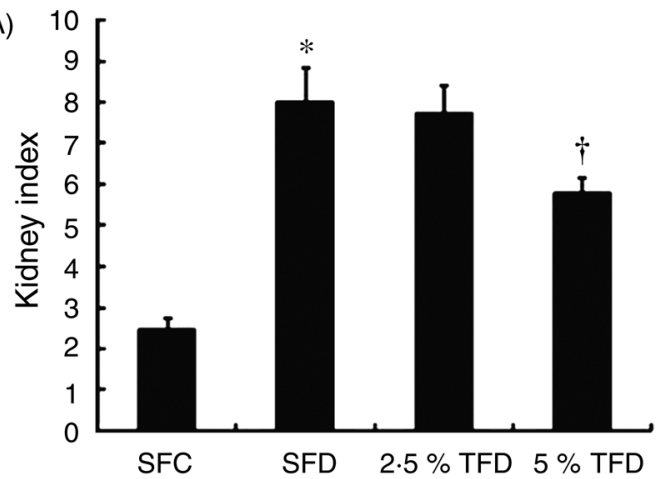

(B)

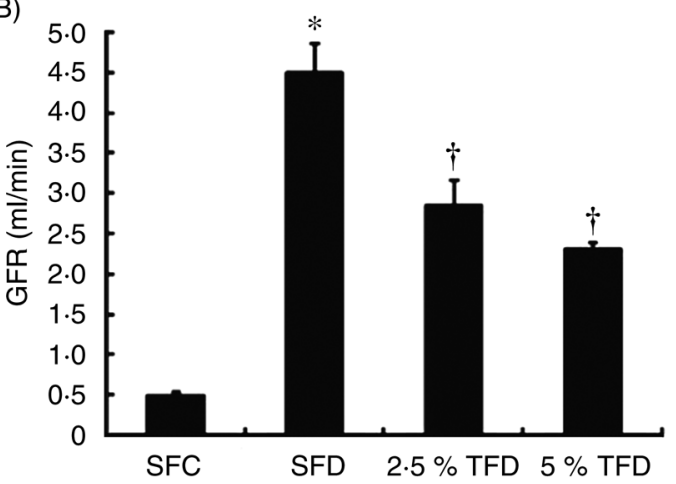

(C)

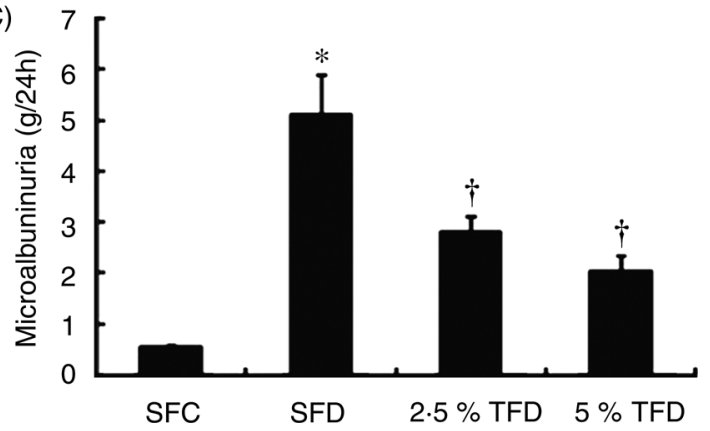

Fig. 1. Effect of Tinospora cordifolia (TC) on kidney index (A), glomerular filtration rate (GFR) (B) and microalbuminuria $(C)$ in control $(n 6)$ and diabetic rats ( $n 11$ per group). SFC, starch-fed control; SFD, starch-fed diabetic; TFD, TC-fed diabetic ( 2.5 and $5 \%$ ). Values are means, with standard deviations represented by vertical bars. * Mean value was significantly different from that of the SFC rats $(P<0.05)$. † Mean value was significantly different from that of the SFD rats $(P<0.05)$.
Effect of Tinospora cordifolia on total sulphated glycosaminoglycan and chondroitin sulphate/dermatan sulphate of diabetic kidney

To determine whether TC feeding had made an impact on GAG in general and CS/DS in particular, they were isolated from kidney as detailed in the 'Materials and methods' section. Quantitative decrease in the total sulphated GAG and CS/DS observed in diabetic animals was significantly ameliorated in TC-fed groups (Fig. 3(A) and (B)). An altered ratio of CS/DS to HS measured by differential digestion of the total GAG with chondroitinase $A B C$ or nitrous acid, observed in diabetic rats was modulated in both 2.5 and $5 \%$ TC-supplemented diabetic rats Fig. 3(C)). Agarose gel electrophoresis was performed to confirm the purity of the CS/DS (data not shown).

Effect of Tinospora cordifolia supplementation on disaccharide composition and hybrid structure of kidney chondroitin sulphate/dermatan sulphate

The purified CS/DS from SFC, SFD and TFD groups was digested with chondroitinase $\mathrm{ABC}$ and subsequent HPLC analysis, after labelling with a fluorophore $2 \mathrm{AB}$ revealed the presence of disaccharides characteristic of

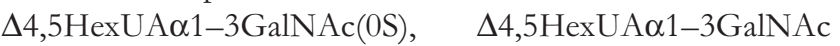
(6S), $\Delta 4,5 \mathrm{HexUA \alpha} 1-3 \mathrm{GalNAc}(4 \mathrm{~S}), \Delta 4,5-\mathrm{HexUA}(2 \mathrm{~S}) \alpha 1-$ $3 \mathrm{GalNAc}(6 \mathrm{~S})$ and $\Delta 4,5 \mathrm{HexUA \alpha} 1-3 \mathrm{GalNAc}(4 \mathrm{~S}, 6 \mathrm{~S})$ (where HexUA stands for hexuronic acid; Fig. 4(A)). The decreased content of $\mathrm{E}$ units ( $25 \%$ compared with SFC), which is characterised by sulphation at 4-O and 6-O positions of GalNAc residues in CS/DS from diabetic rat kidney was modulated in the $5 \%$ TC-fed group. No significant differences were observed with respect to other disaccharides. Furthermore, CS/DS isolated from various groups demonstrated that they were a hybrid molecule with both glucuronic acid and L-iduronic acid-containing molecules. L-Iduronic acid-containing disaccharides were in higher amounts in diabetic rats in all the groups but were marginally decreased in rats fed TC (Fig. 4B).

\section{Effect of Tinospora cordifolia on molecular mass of purified chondroitin sulphate/dermatan sulphate}

The average molecular weight of the purified CS/DS was determined by gel filtration using a column of Superdex 200. It was calibrated using markers of known molecular mass as detailed in the 'Materials and methods section'. The average molecular weight of purified CS/DS from rat kidney of control animals was found to be $38 \mathrm{kDa}$ and it was decreased to $29 \mathrm{kDa}$ in diabetic rat kidney (Fig. 5). However, in rats fed $5 \% \mathrm{TC}$, the chain length was 38 $\mathrm{kDa}$ akin to control animals. The molecular masses of the purified CS/DS in control rats were high as compared with those of DS from hagfish notochord $(18 \mathrm{kDa})^{(37)}$, porcine skin $(19 \mathrm{kDa})$, eel skin $(14 \mathrm{kDa})^{(38)}$ and endocan of endothelial cells $(30 \mathrm{kDa})^{(39)}$. 
(A)
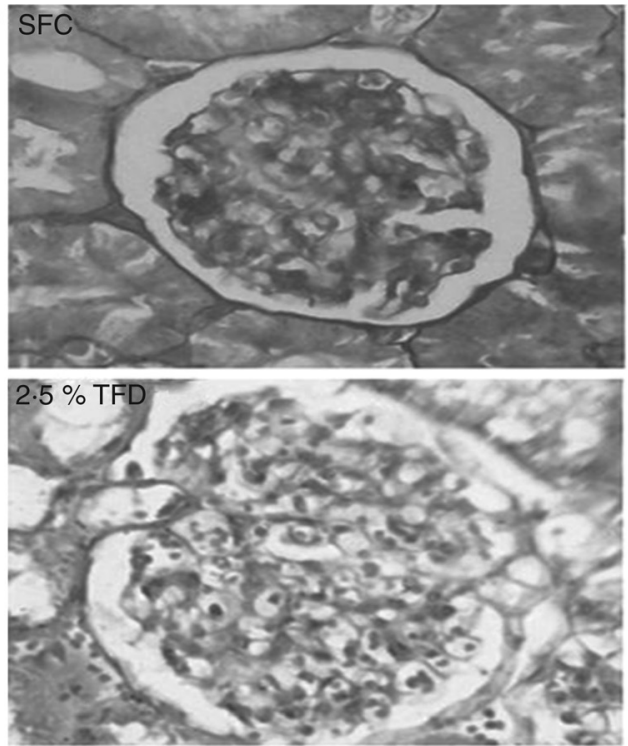
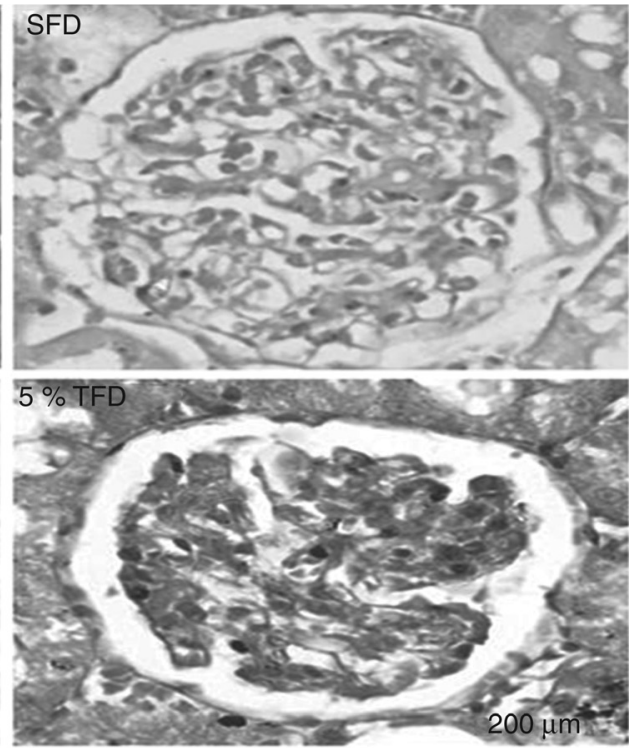

(B)

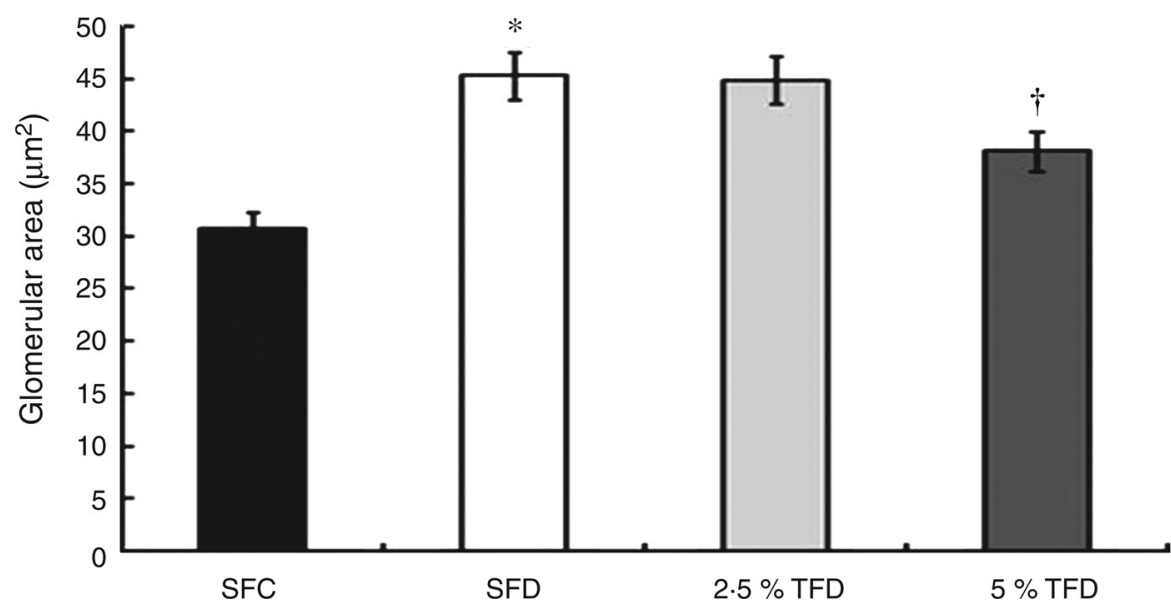

Fig. 2. Glomerular area of kidney from control, diabetic and Tinospora cordifolia (TC)-fed rats. (A) Kidneys were paraffin blocked and 5 um sections were made. These paraffin sections were hydrated and stained with haematoxylin and eosin as detailed in the Experimental methods section. The areas of glomerulus were calculated using Image J software (B). Analysis was carried out for at least twenty glomeruli per rat. SFC, starch-fed control; SFD, starch-fed diabetic; TFD, TCfed diabetic (2.5 and $5 \%$ ). Values are means, with standard deviations represented by vertical bars, for control rats ( $n 6)$ and diabetic rats ( $n 11$ per group). * Mean value was significantly different from that of the SFC rats $(P<0.05)$. $†$ Mean value was significantly different from that of the SFD rats $(P<0.05)$.

Effect of Tinospora cordifolia on mRNA expression of chondroitin 4-0-sulfotransferase-1, dermatan

4-0-sulfotransferase-1 and $\mathrm{N}$-acetylgalactosamine 4 sulphate 6-O-sulfotransferase involved in the synthesis of the ' $E$ ' unit of chondroitin sulphate/dermatan sulphate

To determine whether the synthesis of E-disaccharide units is affected, by feeding TC-diet on mRNA expression of chondroitin 4-O-sulfotransferase-1, dermatan 4-O-sulphotransferase-1 and $\mathrm{N}$-acetylgalactosamine 4 sulphate 6-O-sulfotransferase sulfotransferase was determined. The decreased expression of all the three biosynthetic enzymes during diabetes was ameliorated in rats fed $T C$ to various extents (Fig. 6(A)-(D)).

\section{Effect of Tinospora cordifolia on ligand-binding property of chondroitin sulphate/dermatan sulphate to major extracellular matrix components}

CS/DS, being an ECM component, is known to bind to a plethora of other molecules to elicit a response. In this study, we were interested to know if the decreased binding of CS/DS from diabetic rats to other ECM components is altered in TC-fed rats. Hence, CS/DS preparations (100 ng) from SFC, SFD and TFD rat kidney were individually immobilised onto poly-L-lysine-coated wells and tested for binding to the laminin and type IV collagen by immunoassay as mentioned in the 'Materials and methods' section. Both laminin and type IV collagen binding by CS/DS isolated from $5 \%$ TC-fed rats were positively modulated (Fig. 7(A) and (B)). The binding of type IV collagen and laminin to CS/DS was specific since the binding was completely abrogated on digestion of CS/DS preparations by chondroitinase $\mathrm{ABC}$ (data not shown).

\section{Discussion}

Diabetes is a metabolic disorder that if left untreated results in various secondary complications. Diabetic nephropathy is one such complication which affects the kidney and leads to end- 
(A)

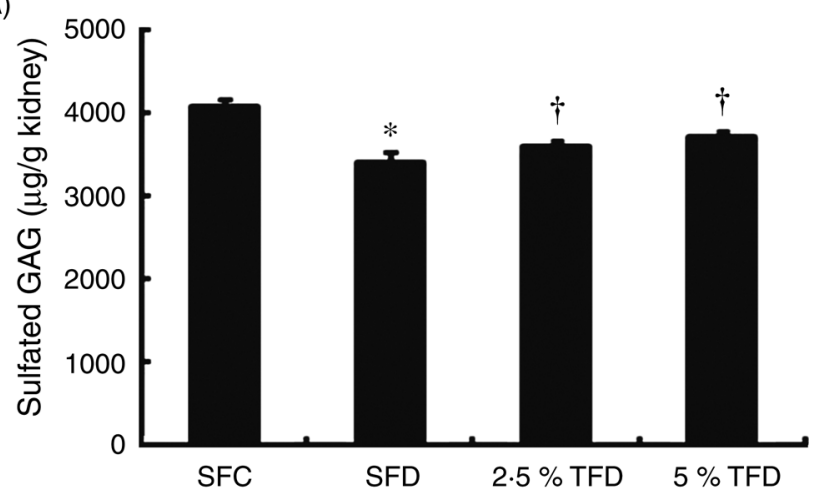

(B)

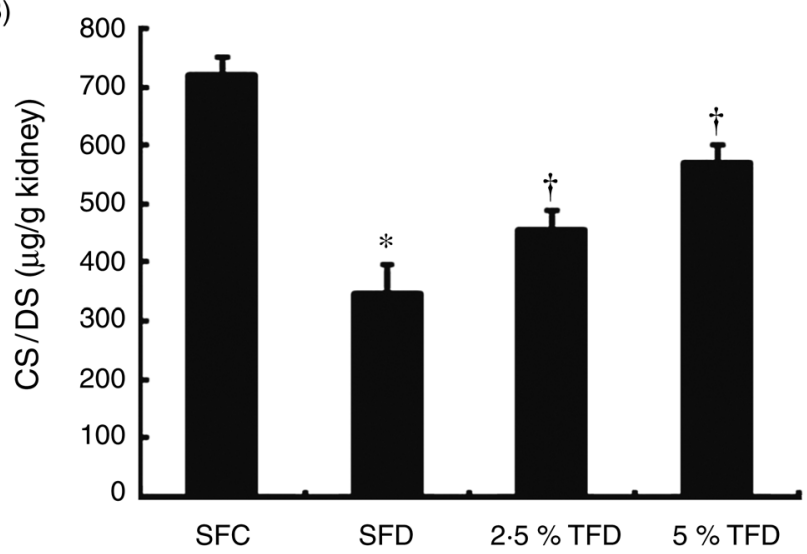

(C)

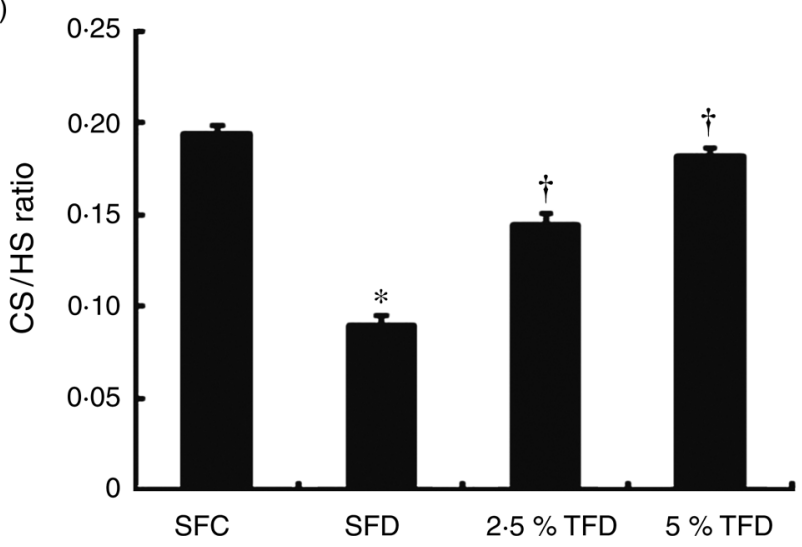

Fig. 3. Sulfated glycosaminoglycans (GAG) in the kidney of control, diabetic and Tinospora cordifolia (TC)-fed diabetic rats. Sulfated GAG were isolated from the kidneys of control, diabetic and TC-fed diabetic rat kidney (A). The amount of chondroitin sulphate/dermatan sulphate (CS/DS) was determined by the 1,9-dimethylmethylene blue (DMMB) assay after differential digestion with either chondroitinase A, B or C (see Experimental methods) (B). Ratio of CS/heparan sulphate (HS) was calculated from the amounts of CS/DS and HS obtained (C). SFC, starch-fed control; SFD, starch-fed diabetic; TFD, TC-fed diabetic (2.5 and $5 \%$ ). Values are means of two independent experiments carried out in triplicates, with standard deviations represented by vertical bars, for pooled control ( $n 6)$, diabetic $(n 11)$ and TCfed diabetic rat kidney $(n 11)$. ${ }^{*}$ Mean value was significantly different from that of the SFC rats $(P<0.05)$. $†$ Mean value was significantly different from that of the SFD rats $(P<0.05)$.

stage renal failure. ECM components are affected during the diabetic condition. These include decreases in GAG such as $\mathrm{HS}$ and $\mathrm{CS} / \mathrm{DS}^{(4,7)}$ and an increase in type IV collagen ${ }^{(5)}$. The qualitative and quantitative changes in ECM components make an impact on the filtration process.

Dietary components/nutraceuticals play an important role in the management of diabetes. ECM components are known to be modulated by various dietary regimens ${ }^{(16,17)}$. In this study, the focus has been on the effect of TC on CS/ DS, an important ECM component present in small but significant amounts in the kidney. CS, which is reportedly present to the tune of $75 \%$ in embryonic kidney, has been implicated in kidney morphogenesis ${ }^{(8)}$ as well as permselective properties ${ }^{(9)}$. Our previous study has shown that diabetes results in structural and functional changes in kidney CS/ $\mathrm{DS}^{(7)}$.

STZ-induced diabetic rats were fed with a normal AIN-76 diet or a diet supplemented with $T C$ stem at two levels, namely 2.5 and $5 \%$. Diets containing TC exerted beneficial effect on blood glucose and urine sugar during diabetes, which is in 
(A)

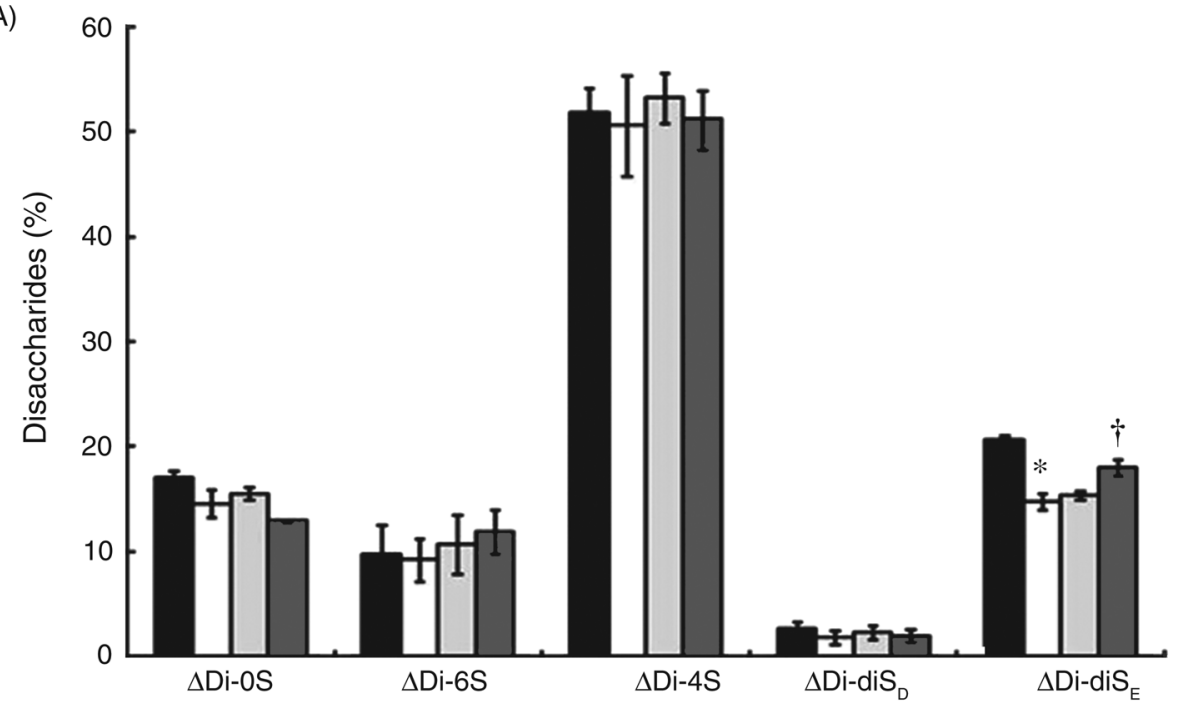

(B)

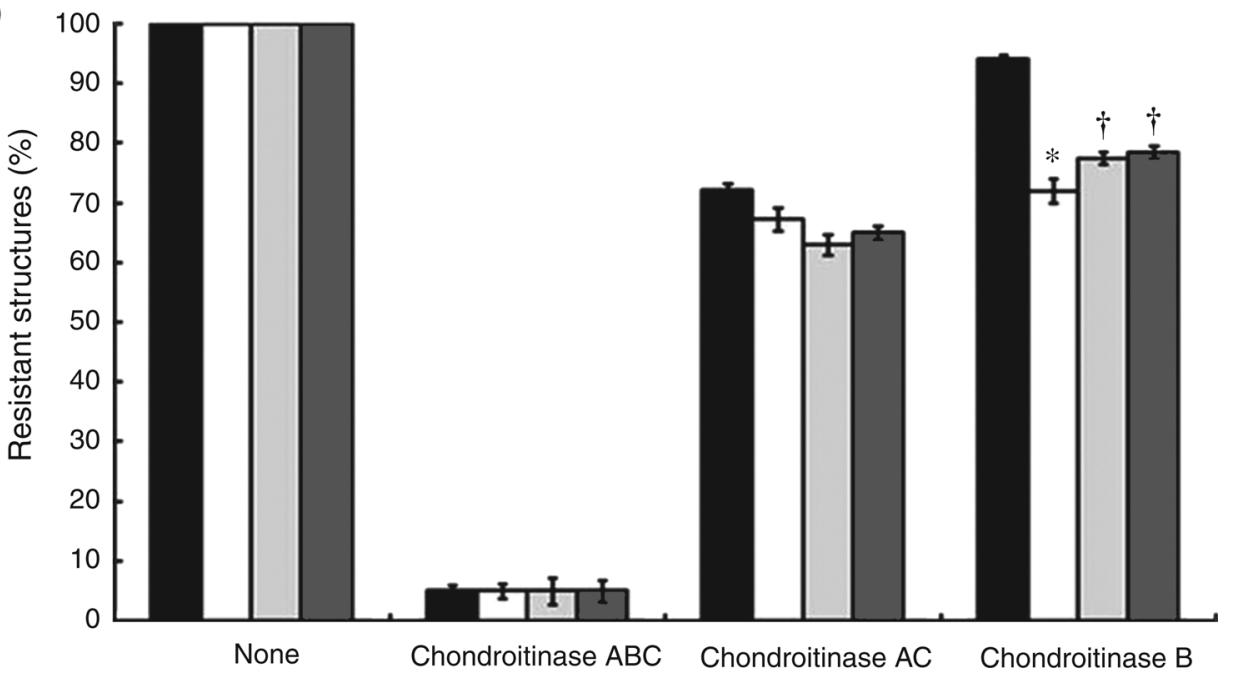

Fig. 4. Disaccharide composition and hybrid structure analysis of kidney chondroitin sulphate/dermatan sulphate (CS/DS) from control diabetic and Tinospora cordifolia (TC)-fed diabetic rats. (A) Isolated glycosaminoglycans (GAG) were subjected to $\mathrm{HNO}_{2}$ digestion followed by gel filtration and hyaluronidase digestion to obtain pure CS/DS. Disaccharide composition analysis was carried out by digesting $4 \mu \mathrm{g}$ (as sulfated GAG) by chondroitinase ABC followed by $2 A B$ labelling and analysed by anion-exchange HPLC on a PA-03 column using a 16-530 mM- $\mathrm{NaH}_{2} \mathrm{PO}_{4}$ gradient over a $1 \mathrm{~h}$ period. Fractions were monitored by fluorescence detection, as detailed in Experimental methods. Peak areas of disaccharides were integrated and expressed as percentages. $\triangle \mathrm{Di}-0 \mathrm{~S},(\Delta 4,5 \mathrm{HexUA \alpha 1-3GalNAc);} \triangle \mathrm{Di}-6 \mathrm{~S}$,

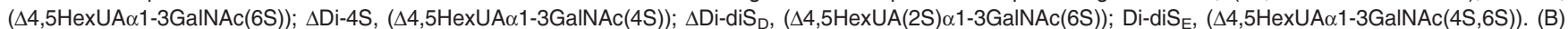
Purified kidney CS/DS (8 $\mu \mathrm{g}$ as sulfated GAG) from all groups was digested with either chondroitinase ABC, AC, B or none. Undigested GAG were estimated by 1,9-dimethylmethylene blue (DMMB) as detailed in Experimental methods. I, Starch-fed control; $\square$, starch-fed diabetic; $(5 \%)$. Values are means of analyses carried out on purified CS/DS preparations of two independent experiments, with standard deviations represented by vertical bars. * Mean value was significantly different from that of the SFC rats $(P<0.05)$. $†$ Mean value was significantly different from that of the SFD rats $(P<0.05)$.

accordance with the reported literature ${ }^{(40)}$. It also imparted beneficial effects on kidney as was clear from evaluation of various parameters such as kidney index, GFR, microalbuminuria and glomerular area. TC-feeding also contained the decreased synthesis of sulphated GAG and CS/DS in kidney. Structurally, the differences in disaccharide composition with respect to the $\mathrm{E}$ disaccharide unit in kidney of diabetic rats was partially prevented in $5 \%$ TC-fed rats but not in $2.5 \%$ $T C$-fed rats though there was amelioration of basic parameters at both levels. In brain, $\mathrm{E}$ units are known to play vital roles in its development ${ }^{(41)}$, presumably by binding to various growth factors ${ }^{(42)}$ although the importance of E-units in kidney is not elucidated yet. Furthermore, a decrease in mRNA expression levels of the enzymes involved in the synthesis of the E-disaccharide unit, namely chondroitin
4-O-sulfotransferase-1, dermatan 4-O-sulphotransferase-1 and $\mathrm{N}$-acetylgalactosamine 4 sulphate 6-O-sulfotransferase, was prevented in $T C$-fed rats. These results reveal that the nutraceuticals could be acting at the molecular level bringing about credible changes through nutrient-gene interactions. Such an interaction has been observed with other nutraceuticals such as genistein ${ }^{(43)}$. This implies that TC can make an impact on diabetes-related complications through multi-step processes. The underlying mechanism responsible for such changes, however, needs to be critically examined.

$T C$ stem is rich in dietary fibre ${ }^{(44)}$ and bioactives such as tannins, flavanoids and phenolic compounds ${ }^{(45)}$ which make it a good source of nutraceuticals when supplemented with diet. Whole stem was taken for the study rather than nutraceuticalrich extract(s) since we were interested in looking into the 


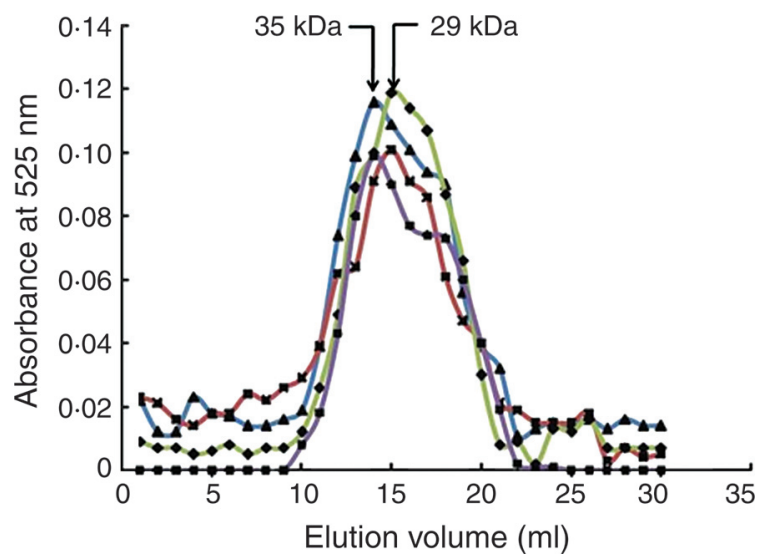

Fig. 5. Molecular weight determination of the purified chondroitin sulphate/ dermatan sulphate (CS/DS). Molecular weight of the purified CS/DS from kidney was determined by gel filtration chromatography on a column of Superdex 200, calibrated with known molecular mass markers as detailed in Experimental methods. Purified CS/DS from control, diabetic and Tinospora cordifolia (TC)-fed groups, $20 \mu \mathrm{g}$ each, was loaded individually onto the Superdex 200 column and the fractions collected and analysed for glycosaminoglycans by complexation with the metachromatic dye, 1,9-dimethylmethy-

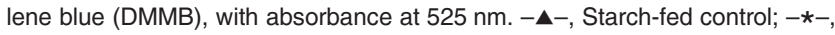
starch-fed diabetic; - - , TC-fed diabetic $(2.5 \%)$; - - -, TC-fed diabetic $(5 \%)$.

modulation of CS/DS in the presence of the constituents of both dietary fibre and nutraceuticals in its natural state. Earlier studies have shown that dietary flavanoids such as anthocyanins, rutin and quercetin are absorbed as glycosides

(A)

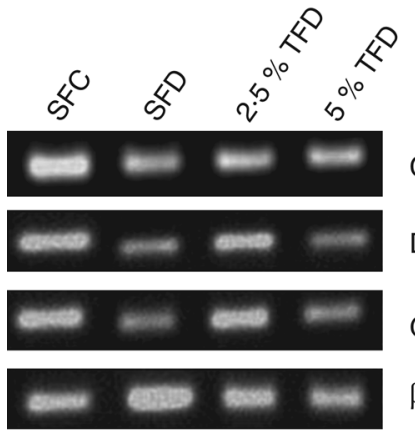

C4ST-1 (611 bp)

D4ST-1 (115 bp)

GalNAc4S-6ST (123 bp)

$\beta-\operatorname{Actin}(285 \mathrm{bp})$

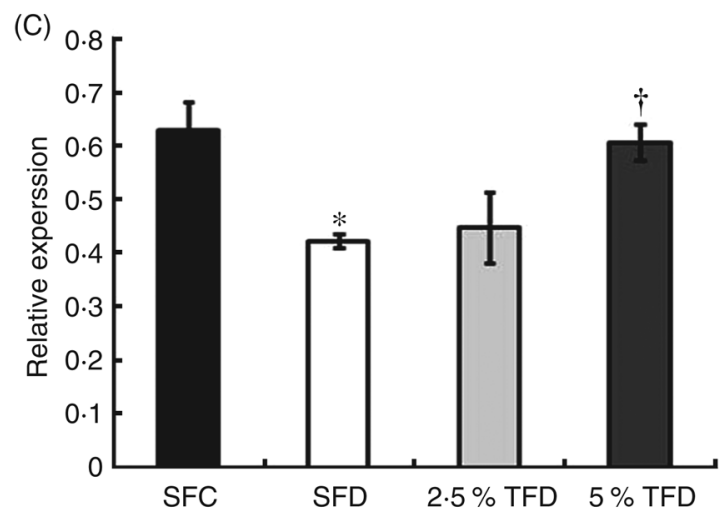

and detected in plasma(46). Anthocyanin was able to be absorbed by the intestine as cyanidin glucosides ${ }^{(47)}$. These reports show that bioactives are absorbed and made available to exert their influence. These nutraceuticals also act as a good source of antioxidants, thus conferring health benefits. During diabetes increased oxidative stress results in fuelling pathological processes including diabetic nephropathy. Oxidative stress has been implicated in changes in GAG metabolism in tissues such as the aorta, liver and heart ${ }^{(48)}$. Reactive oxygen species in connective tissues have been shown to depolymerise $\mathrm{CS}^{(49)}$. This could be one of the reasons for the decrease of CS/DS during diabetes observed by us in the kidney. This was ameliorated by feeding diet containing $T C$ stem, which indicates that sources rich in antioxidants are beneficial. Wild blueberry consumption was shown to affect composition and structure of GAG in rat aorta which gives credence to the fact that nutraceuticals can influence GAG metabolism ${ }^{(50)}$. Other plantderived micronutrients such as ascorbic acid, quercetin, gotu kola extract (10\% asiatic acid), green tea extract (40\% epigallocatechin gallate), or a mixture of these micronutrients for 48 $\mathrm{h}$ are also reported to modulate ECM composition ${ }^{(51)}$.

Apart from modulation of CS/DS by bioactives, dietary fibre also plays a vital role in ameliorating pathological conditions. Our previous study showed that dietary fibres are able to ameliorate decreased synthesis of HS in diabetic rat kidney ${ }^{(16)}$. The action of dietary fibre can be through two modes. Firstly, it prevents rapid digestion and absorption of glucose, and secondly,
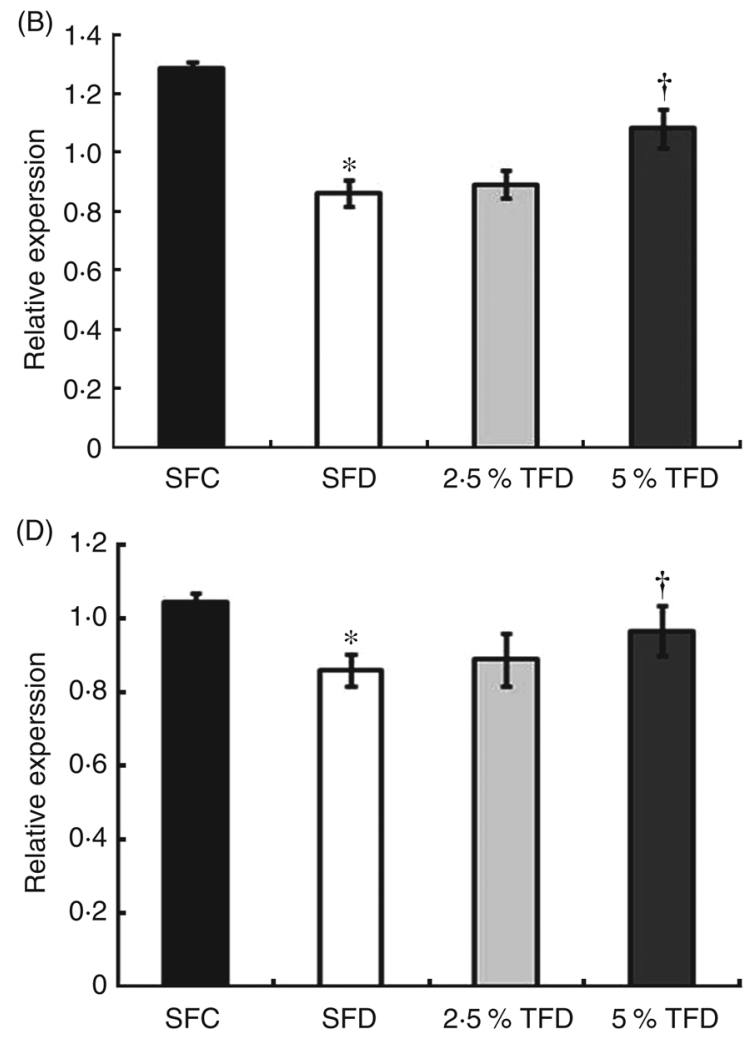

Fig. 6. mRNA expression of chondroitin 4-O-sulfotransferase (C4ST-1), dermatan 4-O-sulfotransferase (D4ST-1) and $\mathrm{N}$-acetylgalactosamine 4 sulfate 6-O-sulfotransferase (GalNAc4S-6ST) in kidney. Total RNA was isolated, reverse transcribed and amplified by adding requisite primers. Amplicon size was observed by agarose gel electrophoresis (A). Bands were quantified by densitometry using Win-32 software and normalised against actin which was used as an internal control. The expression of mRNA was evaluated for C4ST-1 (B), D4ST-1 (C) and GalNAc4S-6ST (D). Expression was carried out in triplicates for at least five animals per group. SFC, starch-fed control; SFD, starch-fed diabetic; TFD, Tinospora cordifolia-fed diabetic ( 2.5 and $5 \%$ ). Values are means, with standard deviations represented by vertical bars. * Mean value was significantly different from that of the SFC rats $(P<0.05)$. $\dagger$ Mean value was significantly different from that of the SFD rats $(P<0.05)$. 

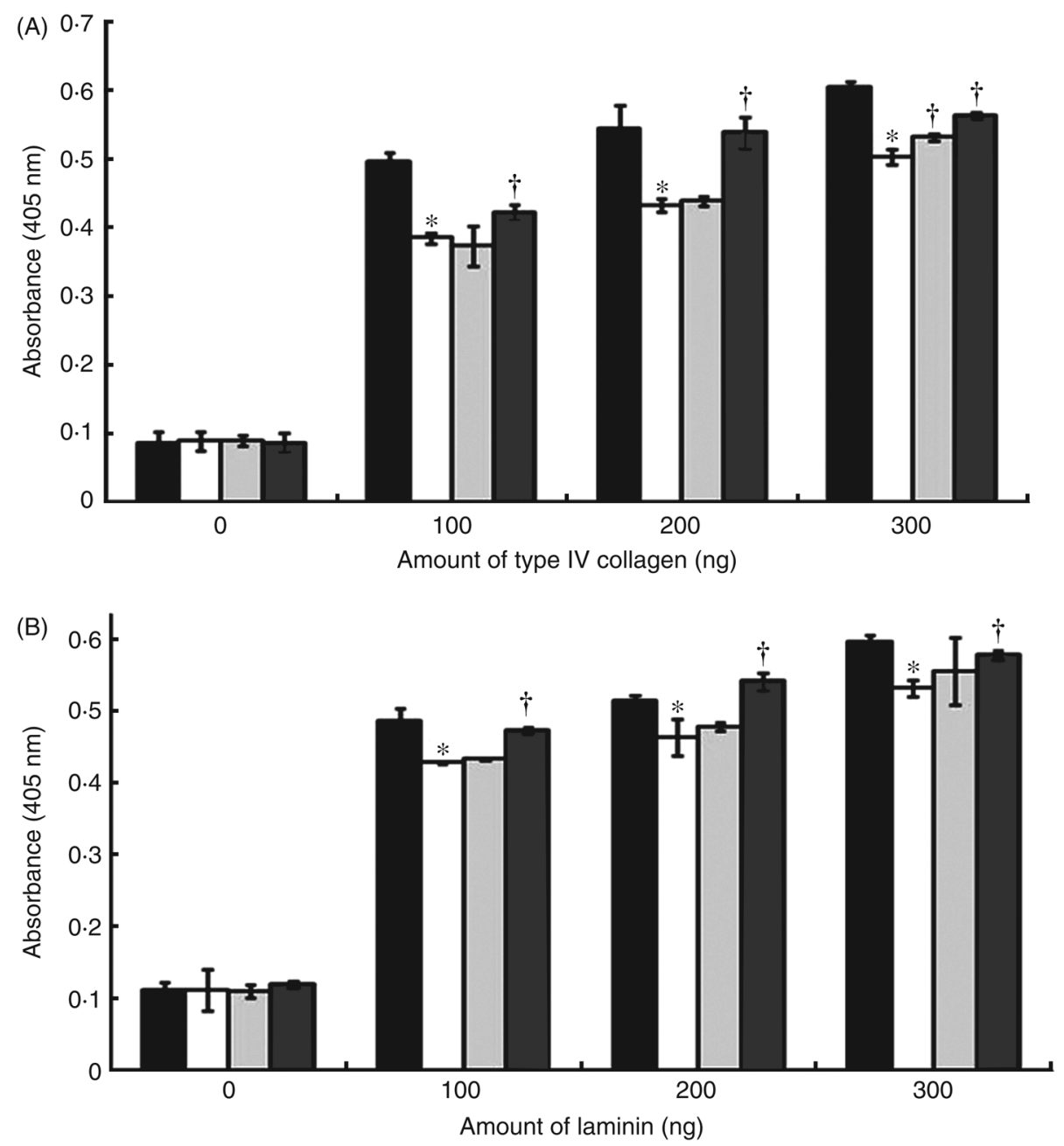

Fig. 7. Binding of purified chondroitin sulphate/dermatan sulphate (CS/DS) to extracellular matrix components. Purified CS/DS from the kidney of control, diabetic and Tinospora cordifolia (TC)-treated rats was immobilised in a ninety-six-well plate with prior coating of poly-L-lysine as detailed in Experimental methods. Extracellular matrix components such as type IV collagen (A) and laminin (B) in varying amounts were evaluated for binding to CS/DS by immunoassay. $\square$, Starch-fed control; $\square$, starch-fed diabetic; deviations represented by vertical bars. * Mean value was significantly different from that of the SFC rats $(P<0.05)$. $†$ Mean value was significantly different from that of the SFD rats $(P<0.05)$.

through the action of metabolites of dietary fibre. Dietary fibres are fermented by intestinal microflora into SCFA such as acetic acid, propionic acid and butyric acid which can then influence metabolic processes ${ }^{(52)}$. Butyrate in particular has been shown to induce insulin gene expression in cell culture system ${ }^{(53)}$ and improve insulin sensitivity and reduce development of obesity by increasing energy expenditure in a high fat-fed diet ${ }^{(54)}$. Since TC stem is rich in dietary fibre $(34 \%)^{(44)}$, it can apparently exert its influence through the ways mentioned earlier.

Lastly, evaluation of function of CS/DS isolated from control, diabetic and treated rat kidney in terms of binding to other ECM components such as type IV collagen and laminin revealed that changes in CS/DS structurally result in changes in functional properties. The decreased binding was ameliorated in CS/DS from kidneys of $5 \%$ TC-fed rats. The modulatory effect of $T C$ could be due to combinatorial effect of dietary fibre and its fermented products - including butyric acid and bioactives present in the stem of TC.

Thus, this study demonstrated that consumption of diet supplemented with $T C$ has beneficial effects in the diabetic condition, which in turn exerts a positive influence on the CS/DS metabolism of the kidney.

\section{Acknowledgements}

D. J. thanks the Indian Council of Medical Research, New Delhi, for the award of a Senior Research Fellowship. This work was supported by a grant-in-aid (SR/SO/HS-28/2009) from the Department of Science and Technology, New Delhi, India. D. J. performed experiments, analysed data and wrote the manuscript. C. D. N. and P. V. S. designed the study, gave technical inputs, analysed and interpreted the data and corrected the manuscript. All the authors read and approved the final version of this manuscript. There are no conflicts of interest whatsoever among the authors.

\section{References}

1. Fowler MJ (2008) Microvascular and macrovascular complications of diabetes. Clin Diab 26, 77-82. 
2. Zelmanovitz T, Gerchman F, Balthazar AP, et al. (2009) Diabetic nephropathy. Diabetol Metab Syndr 21, 1-10.

3. Maxhimer JB, Somenek M, Rao G, et al. (2005) Heparanase-1 gene expression and regulation by high glucose in renal epithelial cells: a potential role in the pathogenesis of proteinuria in diabetic patients. Diabetes 54, 2172-2178.

4. Shimomura H \& Spiro R (1987) Studies on macromolecular components of human glomerular basement membrane and alterations in diabetes: decreased levels of heparan sulfate proteoglycans and laminin. Diabetes 36, 374-381.

5. Mason RM \& Wahab NA (2003) Extracellular matrix metabolism in diabetic nephropathy. J Am Soc Nephrol 14, 1358-1373.

6. Silbert JE \& Sugumaran G (2002) Biosynthesis of chondroitin/dermatan sulfate. IUBMB Life 54, 177-186.

7. Joladarashi D, Salimath PV \& Nandini CD (2011) Diabetes results in structural alteration of chondroitin sulfate/dermatan sulfate in the rat kidney: effects on the binding to extracellular matrix components. Glycobiology 21, 960-972.

8. Steer DL, Shah MM, Bush KT, et al. (2004) Regulation of ureteric bud branching morphogenesis by sulfated proteoglycans in the developing kidney. Dev Biol 272, 310-327.

9. Jeansson M \& Haraldsson B (2003) Glomerular size and charge selectivity in the mouse after exposure to glucosaminoglycandegrading enzymes. J Am Soc Nephrol 14, 1756-1765.

10. Haneda M, Koya D, Isono M, et al. (2003) Overview of glucose signalling in mesangial cells in diabetic nephropathy. J Am Soc Nephrol 14, 1374-1382.

11. Puranik NK, Kammar KF \& Sheela DR (2010) Anti-diabetic activity of Tinospora cordifolia (Willd.) in streptozotocin diabetic rats; does it act like sulfonylureas? Turk J Med Sci 40, 265-270.

12. Gray AM \& Flatt PR (1997) Nature's own pharmacy: the diabetes perspective. Proc Nutr Soc 56, 507-517.

13. Suresh Kumara G, Shetty AK \& Salimath PV (2008) Modulatory effect of bitter gourd (Momordica charantia LINN.) on alterations in kidney heparan sulfate in streptozotocin-induced diabetic rats. J Ethnopharmacol 115, 276-283.

14. Kameswararao B, Kesavulu MM \& Apparao C (2003) Evaluation of antidiabetic effect of Momordica cymbalaria fruit in alloxan-diabetic rats. Fitotherapia $74,7-13$.

15. Cencic A \& Chingwaru W (2010) The role of functional foods, nutraceuticals, and food supplements in intestinal health. Nutrients 2, 611-625.

16. Nandini CD, Sambaiah K \& Salimath PV (2003) Dietary fibres ameliorate decreased synthesis of heparan sulfate in streptozotocin induced diabetic rats. J Nutr Biochem 14, 203-210.

17. Kumar PA, Nandini CD \& Salimath PV (2011) Structural characterization of $\mathrm{N}$-linked oligosaccharides of laminin from rat kidney: changes during diabetes and modulation by dietary fiber and butyric acid. FEBS J 278, 143-155.

18. Chopra RN, Chopra LC, Handa KD, et al., editors (1982) Indigenous Drugs of India, 2nd ed., pp. 426-428. Kolkota: M/S Dhar VN \& Sons.

19. Gupta SS, Verma SC, Garg VP, et al. (1967) Antidiabetic effects of Tinospora cordifolia. Part 1. Effect on fasting blood sugar level, glucose tolerance and adrenaline induced hyperglycaemia. Indian J Med Res 55, 733-745.

20. Atal CK, Sharma ML \& Kaul A (1986) Immunomodulating agents of plant origin. I: preliminary screening. J Ethnopharmacol 18, 133-141.

21. Peer F \& Sharma MC (1989) Therapeutic evaluation of Tinospora cordifolia in $\mathrm{CCl} 4$ induced hepatopathy in goats. Indian J Vet Med $\mathbf{9}$, 154-156.

22. Vedavathy S \& Rao KN (1991) Antipyretic activity of six indigenous medicinal plants of Tirumala Hills Andhra Pradesh, India. J Ethnopharmacol 33, 1-2.

23. Bieri JG, Stoewsand GS, Briggs GM, et al. (1997) Report of the American institute of nutrition, ad hoc committee on standards for nutritional studies. J Nutr 107, 1340-1348.
24. Hatch GM, Cao SG \& Angel A (1995) Decrease in cardiac phosphatidyl glycerol in streptozotocin induced diabetic rats does not affect cardiolipin biosynthesis. Evident for distant pools of phospolipid glycerol in the heart. Biochem J 306, 759-764.

25. Bowers LD (1980) Kinetic serum creatinine assays I. The role of various factors in determining specificity. Clin Chem 26, 551-554.

26. Yokozawa T, Chung HY, He LQ, et al. (1996) Effectiveness of green tea tannin on rats with chronic renal failure. Biosci Biotechnol Biochem 60, 1000-1005.

27. Kessler MA, Meinitzer A, Petek W, et al. (1997) Microalbuminuria and borderline-increased albumin excretion determined with a centrifugal analyzer and the Albumin Blue 580 fluorescence assay. Clin Chem 43, 996-1002.

28. Scott JE (1960) Aliphatic ammonium salts in the assay of acidic polysaccharides from tissues. Methods Biochem Anal 8, 145-197.

29. Shively JE \& Conrad HE (1976) Formation of anhydrosugars in the chemical depolymerization of heparin. Biochemistry 15, 3932-3942.

30. Chandrasekhar S, Esterman MA \& Hoffman H (1987) A microdetermination of proteoglycan and glycosaminoglycans in the presence of guanidine hydrochloride. Anal Biochem 161, 103-108.

31. Saito H, Yamagata T \& Suzuki S (1968) Enzymatic methods for the determination of small quantities of isomeric chondroitin sulfates. J Biol Chem 243, 1536-1542.

32. Kinoshita A \& Sugahara K (1999) Microanalysis of glycosaminoglycan-derived oligosaccharides labeled with a fluorophore 2 -aminobenzamide by high-performance liquid chromatography: Application to disaccharide composition analysis and exosequencing of oligosaccharides. Anal Biochem 269, 367-378.

33. Bigge JC, Patel TP, Bruce JA, et al. (1995) Non-selective and efficient fluorescent labelling of glycans using 2 -aminobenzamide and anthranilic acid. Anal Biochem 230, 229-238.

34. Farndale RW, Buttle DJ \& Barrett AJ (1986) Improved quantitation and discrimination of sulfated glycosaminoglycans by use of dimethylmethylene blue. Biocbim Biophys Acta 883, 173-177.

35. Hugget ASG \& Nixon DA (1957) Use of glucose oxidase, peroxidase and $\mathrm{O}$-dianisidine in the determination of blood glucose and urinary glucose. Lancet 273, 366-370.

36. Miller GL (1959) Use of dinitrosalicylic acid reagent for determination of reducing sugar. Anal Chem 31, 426-428.

37. Nandini CD, Mikami T, Ohta M, et al. (2004) Structural and functional characterization of oversulfated chondroitin sulfate/dermatan sulfate hybrid chains from the notochord of hagfish neuritogenic and binding activities for growth factors and neurotrophic factors. J Biol Chem. 279, 50799-50809.

38. Sakai S, Kim WS, Lee IS, et al. (2003) Purification and characterization of dermatan sulfate from the skin of the eel, Anguilla japonica. Carbobydr Res 31, 263-269.

39. Bechard D, Gentina T, Delehedde M, et al. (2001) Endocan is a novel chondroitin sulfate/dermatan sulfate proteoglycan that promotes hepatocyte growth factor/scatter factor mitogenic activity. J Biol Chem 21, 48341-48349.

40. Rajalakshmi M, Eliza J, Priya CE, et al. (2009) Anti-diabetic properties of Tinospora cordifolia stem extracts on streptozotocin-induced diabetic rats. Afr J Pharm Pharmacol 3, 171-180.

41. Purushothaman A, Fukuda J, Mizumoto S, et al. (2007) Functions of chondroitin sulfate/dermatan sulfate chains in brain development. Critical roles of $\mathrm{E}$ and $\mathrm{i} \mathrm{E}$ disaccharide units recognized by a single chain antibody GD3G7. J Biol Chem 282, 19442-19452.

42. Deepa SS, Umehara Y, Higashiyam S, et al. (2002) Specific molecular interactions of oversulfated chondroitin sulfate $E$ with various heparinbinding growth factors. Implications as a physiological binding partner in the brain and other tissues. J Biol Chem 277, 43707-43716.

43. Schleipen B, Hertrampf T, Fritzemeier K, et al. (2011) ER \{beta\}specific agonists and genistein inhibit proliferation and induce apoptosis in the large and small intestine. Carcinogenesis 11, 1675-1683.

44. Bhawya D \& Anilkumar KR (2010) In vitro antioxidant potency of Tinospora cordifolia (gulancha) in sequential extracts. IJPBA 5, 448-456. 
45. Panchabhai TS, Kulkarni UP \& Rege NN (2008) Validation of therapeutic claims of Tinospora cordifolia: a review. Phytother Res 22, 425-441.

46. Paganga G \& Rice-Evans CA (1997) The identification of flavanoids as glycosides in human plasma. FEBS Lett 13, 78-82.

47. Wu X, Cao G \& Prior RL (2002) Absorption and metabolism of anthocyanins in human subjects following consumption of elderberry or blueberry. J Nutr 132, 1865-1871.

48. Latha MS, Vijayammal PL \& Kurup PA (1991) Charges in the glycosaminoglycans and glycoproteins in the tissues in rats exposed to cigarette smoking. Atherosclerosis 31, 49-54.

49. Volpi N \& Tarugi P (1999) Influence of chondroitin sulfate charge density, sulfate group position and molecular mass on $\mathrm{Cu}+2$ mediated oxidation of human low density lipoproteins: effect of normal human plasma derived chondroitin sulfate. $J$ Biol Chem $125,297-304$
50. Kalea AZ, Lamari FN, Theocharis AD, et al. (2006) Wild blueberry (Vaccinium angustifolium) consumption affects the composition and structure of glycosaminoglycans in Sprague-Dawley rat aorta. J Nutr Biochem 17, 109-116.

51. Ivanov V, Ivanova S, Kalinovsky T, et al. (2008) Plant-derived micronutrients suppress monocyte adhesion to cultured human aortic endothelial cell layer by modulating its extracellular matrix composition. J Cardiovasc Pharmacol 52, 55-65.

52. Smith JG, Yokoyama WH \& German JB (2000) Butyric acid from the diet: actions at the level of gene expression. Crit Rev Food Sci38, 259-297.

53. Karlsen AE, Fujimoto WY, Rabinovitch P, et al. (1991) Effects of sodium butyrate on proliferation-dependent insulin gene expression and insulin release in glucose-sensitive RIN-5AH cells. J Biol Chem 266, 7542-7548.

54. Gao Z, Yin J, Zhang J, et al. (2009) Butyrate improves insulin sensitivity and increases energy expenditure in mice. Diabètes 58, 1509-1517. 